\title{
Produção e utilização da silagem de planta inteira de soja (Glicine max) para ruminantes
}

\author{
Production and use of the ensilage of entire soy palnt (Glicine max) for \\ ruminants
}

\author{
Suelen Túlio Córdova Gobetti' \\ Mikael Neumann ${ }^{2(*)}$ \\ Marcos Rogério Oliveira ${ }^{3}$ \\ Rodrigo Oliboni ${ }^{4}$
}

\section{Resumo}

Objetivou-se descrever as características quantitativas e qualitativas referentes à cultura da soja (Glicine max), com a finalidade de silagem de planta inteira. No Brasil, a área cultivada de soja na safra de 2010/2011, de acordo com dados da Embrapa (2011) foi de 24,2 milhões de hectares. A irregularidade da ocorrência de chuvas tem inviabilizado economicamente muitas lavouras de soja para a produção de grãos pela diminuição da produtividade e aumento dos custos da produção, possibilitando a utilização da planta inteira de soja como silagem para a alimentação animal. As vantagens da utilização da silagem de planta inteira de soja em comparação a de outras gramíneas como o milho e o sorgo estão nos maiores valores médios encontrados, de $18 \%$ proteína bruta, 31\% de matéria seca, 32\% de fibra em detergente ácido e $41 \%$ de fibra em detergente neutro, 23\% de extrato etéreo e produtividade média de sete toneladas por hectare, onde a participação de grãos na silagem representa $35 \%$, permitindo que o produtor possa agregar maior valor ao seu produto final e não ficar dependente dos preços alternados do mercado interno na safra e da elevação do preço na entressafra para compra dos subprodutos do processamento da soja, tendo como principal limitação à competição da silagem de soja com a venda dos grãos.

Palavras-chave: silagem de soja; silagem de planta inteira; ruminantes.

I MSc.; Médica Veterinária; Doutoranda em Ciência Animal na Universidade Estadual de Londrina, UEL; Londrina, Paraná, Brasil; E-mail: suellencordova@hotmail.com

2 Dr.; Engenheiro Agrônomo; Professor do Curso de Pós-Graduação em Produção Vegetal da Universidade Estadual do Centro-Oeste, UNICENTRO; Endereço: Rua Simeão Camargo Varela de Sá, 03, CEP: 85.040080, Guarapuava, Paraná, Brasil; E-mail: mikaelneumann@hotmail.com (*) Autor para correspondência.

3 MSc.; Médico Veterinário; Doutorando em Zootecnia na Universidade Estadual de Maringá, UEM; Maringá, Paraná, Brasil; E-mail: oliveira.marcos.r@gmail.com

4 MSc.; Engenheiro Agrônomo da OR Melhoramentos de Sementes Ltda; Passo Fundo, Rio Grande do Sul, Brasil; E-mail: roliboni@hotmail.com 


\section{Abstract}

The aim of the study was to describe the quantitative and qualitative characteristics referring to the culture of the soy (Glicine max), with the purpose of ensilage of entire plant. In Brazil, the cultivated area of soy in 2010/2011, according to data by Embrapa (2011) was 24,2 million hectares. The irregularity of the rain occurrence has made impracticable economically many soy crops for the production of grains for the reduction of the productivity and increase of the costs of the production, having made possible the use of the entire plant of soy as ensilage for the animal feeding. The advantages of using ensilage of entire soy plant in comparison to other grassy ones, as the zea and sorghum ones, are the biggest joined average values, of $18 \%$ crude protein, $31 \%$ of dry substance, $32 \%$ of acid detergent fiber and $41 \%$ of neutral detergent fiber, $23 \%$ of ether extract and average productivity of seven tons per hectare, where the participation of grains in the ensilage represents $35 \%$, allowing the producer to add greater value to its final item and not to be dependent on the alternating prices of domestic market in harvest and on the increase in price during the period between harvests in order to purchase by-products of the soy processing, having as main limitation the competition between soy ensilage and grains sales.

Key words: soybean ensilage; whole plant ensilage; ruminants.

\section{Introdução}

A forma mais fácil para alimentar ruminantes com volumoso é por meio da forragem em pastejo. A disponibilidade de forragem no Brasil é variável durante o ano e depende de condições climáticas, tendo sua produção concentrada nos períodos de verão, reduzindo seu crescimento no inverno, gerando a necessidade de se armazenar forragem conservada para suplementar os animais nos períodos de baixa produção das pastagens. Essa suplementação pode ser feita através da silagem de soja, em cultivo isolado, na entrelinha ou em consórcio com outras culturas, sendo uma alternativa ao produtor, tendo seus custos de produção mais baixos do que a suplementação a base de concentrados, além de ser uma alternativa de venda diferenciada da planta de soja (EVANGELISTA et al., 2003).
O balanceamento de dietas animais suplementados com volumoso a base de silagens de gramíneas normalmente é feito com concentrados protéicos à base de farelo de soja ou de algodão, o que onera bastante a produção animal nas propriedades, em razão de serem subprodutos originários das indústrias de óleos. Pelo exposto, a utilização da soja na forma de forragem pode ser uma alternativa viável para elevar o teor de proteína do volumoso para uso na alimentação de animais, em períodos críticos de disponibilidade de forragem (EVANGELISTA et al., 2003).

A soja grão constitui uma espécie de grande interesse econômico, em função dos teores elevados de proteína (40\%) e extrato etéreo (20\%), da produtividade de grãos e da possibilidade de adaptação a ambientes diversos. É uma cultura anual de autopolinização, pertencente à família 
Fabaceae, gênero Glycine, subgênero Soja e espécie Glicine Max (L.) Merrill (ROCHA, 2002).

O objetivo desta revisão é demonstrar a importância da soja como planta forrageira para alimentação animal na forma de silagem de planta inteira.

\section{Histórico}

A soja que hoje cultivamos é muito diferente das ancestrais, caracterizadas por plantas rasteiras que se desenvolviam na costa leste da Ásia, principalmente ao longo do rio Yangtse, na China. Sua evolução começou com o aparecimento de plantas oriundas de cruzamentos naturais entre duas espécies de soja selvagem que foram domesticadas e melhoradas por cientistas da antiga China (EMBRAPA, 2007).

As primeiras citações sobre o uso do grão de soja na alimentação humana aparecem no período entre 2883 e 2838 $\mathrm{AC}$, quando a soja era considerada um grão sagrado, ao lado do arroz, do trigo, da cevada e do milheto. Um dos primeiros registros do grão está no livro "Pen Ts’ao Kong Mu", que descrevia as plantas da China ao Imperador Sheng-Nung. Até aproximadamente de 1894, término da guerra entre a China e o Japão, o cultivo de soja ficou restrito à China. Apesar de ser conhecida e consumida pela civilização oriental por milhares de anos, só foi introduzida na Europa no final do século $\mathrm{XV}$, como curiosidade, nos jardins botânicos da Inglaterra, França e Alemanha (EMBRAPA, 2007).

No Brasil, o cultivo da soja iniciou no Rio Grande do Sul no início do século passado, trazida dos Estados Unidos e até aproximadamente a década de 1950 seu uso restringiu-se a alimentação de suínos. A partir de 1957, com as freqüentes frustrações da lavoura de trigo, iniciou sua escalada como sustentáculo da economia de milhares de famílias rurais. Com bom preço, forte mercado consumidor, ganhou rapidamente a adesão dos produtores, experimentando um acelerado aumento de área de cultivo, tendo como fato positivo a proteção que oferece a terra, durante o ciclo vegetativo, com sua massa verde cobrindo toda a superfície e, ainda, por ser leguminosa, enriquece do solo com nitrogênio através de processos biológicos (FRANCO, 2004).

Hoje, a soja é um dos principais produtos de exportação do Brasil e uma das principais commodities do mundo. A sua proteína é grandemente utilizada na alimentação animal e seu óleo na alimentação humana (FRANCO, 2004; EMBRAPA, 2007)

Diante exposto, verifica-se que a planta de soja tem uma ampla utilização tanto na alimentação animal como humana, além do largo uso industrial. $\mathrm{Na}$ atualidade, em que os custos de produção estão aumentando na pecuária leiteira, os agropecuaristas vêem na soja uma alternativa para a produção de alimento animal a custos menores na própria fazenda (CORTE et al., 2003).

Um dos maiores problemas enfrentados na pecuária nacional, por ser a pasto, é a degradação das pastagens. Em uma pastagem degradada a produtividade está em torno de duas arrobas/ha/ano, enquanto que em uma pastagem bem manejada e em bom estado pode atingir, em média, dezesseis arrobas/ha/ ano. Desta forma, uma maneira de diminuir os custos com a recuperação ou formação de pastagens é através do plantio da gramínea com uma cultura de grãos (BARBOSA et al., 2007).

Podemos antecipar o cultivo da soja para permitir o plantio da segunda safra do milho. Apesar de ser mais suscetível a 
intempéries do clima, a soja precoce (ciclo menor que 120 dias) passou a ter vantagens importantes depois da disseminação da ferrugem asiática. Isso porque o plantio antecipado desta variedade dribla o surgimento da doença nas fases iniciais de desenvolvimento da planta, economizando de 1 a 1,5 aplicações de fungicidas, não concorrendo dessa forma com a cultura principal da propriedade, tendo como desvantagem a produção de $10 \%$ menos que a cultura de ciclo médio (EMBRAPA, 2008).

\section{Produção de soja no Brasil}

A soja é o $4^{\circ}$ grão mais produzido no mundo, atrás do milho, trigo e arroz. É, portanto, a oleaginosa mais cultivada. Os Estados Unidos da América do Norte é o país que detém a maior produção no contexto mundial, com produção de 90,6 milhões de toneladas. $\mathrm{O}$ Brasil tem se destacado como o segundo maior produtor e exportador de grãos da leguminosa nos últimos anos, tendo, produzido 75 milhões de toneladas na safra de 2010/2011 e exportado 29,1 milhões de toneladas em grãos, 13,7 milhões de toneladas em farelo e 1,6 milhões de toneladas em óleo. Dentre os 14 estados maiores produtores destacam-se, por ordem de produção, como $1^{\circ}$ e $2^{\circ}$ lugares, o Mato Grosso e o Paraná com, respectivamente, 20,4 e 15,4 milhões de toneladas (EMBRAPA, 2011).

A cultura da soja expandiu-se rapidamente no Brasil nas últimas décadas. $\mathrm{Na}$ década de 70, a cultura ocupava uma área de aproximadamente 1,3 milhões de hectares no país. $O$ crescimento foi tanto que, segundo o IBGE (2011), em maio de 2011, a produção de 74,3 milhões de toneladas é recorde, sendo 2,0\% maior que a constatada em abril. Este ganho se deve a uma reavaliação positiva da área em $0,2 \%$ e, especialmente, ao rendimento médio que cresceu $1,8 \%$, devido ao maior uso de tecnologia e às condições climáticas favoráveis nos principais centros produtores.

\section{Silagem de planta inteira de soja}

\section{Uso de soja exclusiva para silagem}

O uso de plantas inteiras de soja na forma de silagem surgiu em 1995, no Uruguai, conforme relato de Franco (2004), com armazenagem em silos do tipo "tubo" de 60 metros de comprimento por 2,8 metros de diâmetro, onde com abertura do silo, o material mostrou bom valor nutricional e pôde ser fornecido normalmente aos animais, ao custo médio de US\$ 0,12 por $\mathrm{kg}$ de matéria seca e teores médios de 18,5\% de proteína bruta.

As recomendações agronômicas para cultivo da soja para silagem são idênticas ao cultivo com o propósito de produção de grãos. Devem-se considerar os rendimentos de massa e a sensibilidade da soja ao fotoperíodo, tendo em vista que cultivares de pequeno porte resultarão em baixa produtividade por área e, assim, para cada região, têm-se cultivares de soja mais adaptadas. Ocorre variação entre cultivares em um mesmo local quanto ao comportamento em relação ao amadurecimento da soja no decorrer do ciclo, tendo cultivares que, com o aumento da matéria seca, do florescimento à formação de grãos, reduzem o teor de proteína mais gradativamente que outras, enfatizando que deve observar-se o melhor momento para colher a soja, aliando rendimento e qualidade da silagem obtida (EVANGELISTA et al., 2003).

O plantio da soja deve ser feito em solo corrigido e com umidade adequada, 
sendo semeada a uma profundidade de três a cinco $\mathrm{cm}$ no período de 10 de outubro a 10 de dezembro, na região Sul do Brasil, com espaçamento entre 30 e $50 \mathrm{~cm}$ para máquinas automotrizes e ensiladeiras de diferentes marcas (KEPLIN, 2004).

$\mathrm{Na}$ cultura da soja, a população de plantas é um fator que pode ser manipulado para se estabelecer uma lavoura que expresse o máximo de rendimento e adaptação estrutural à colheita mecânica, em função de uma máxima interceptação de radiação. Para isso devem-se levar em consideração as exigências da cultivar que se pretende semear, das condições de fertilidade do solo, da época de semeadura e da disponibilidade hídrica durante o ciclo da cultura (KUSS, 2006).

De acordo com a Embrapa (2006) e Kuss (2006), a população de plantas recomendada para a cultura situa-se em torno de 320.000 plantas por hectare. Em geral, estudos desenvolvidos em várias regiões do país demonstraram que variações de $20 \%$, para mais ou para menos neste número não alteraram significativamente o rendimento de grãos.

Segundo as Tecnologias de Produção da Soja (2006) e Embrapa (2011), as cultivares são diferentes quanto à sensibilidade à época de semeadura. Em função disso, algumas apresentam restrições para semeadura em outubro, principalmente em regiões onde se associam altas temperaturas, baixa fertilidade do solo e inverno seco. Nessas condições, semeadura de cultivares precoces em outubro pode resultar em plantas baixas e não fechar bem as entre linhas, havendo maior competição de nutrientes com plantas daninhas, inclusive no final do ciclo, dificultando a colheita. Resultados experimentais e dados de lavouras, obtidos nas regiões sul, sudeste e centro-oeste do
Brasil, têm mostrado maiores rendimentos de grãos, na maioria dos casos, nas semeaduras de segunda quinzena de outubro e do mês de novembro. Cultivares de ciclo mais longo apresentado maior rendimento em semeaduras de outubro e cultivares precoces em semeaduras de novembro.

A distribuição das plantas no campo é feita pela variação do espaçamento e da densidade na linha. Com espaçamento reduzido a cultura atinge mais rapidamente o ponto de fechamento do dossel vegetativo, abafando o crescimento das plantas daninhas. Em condições de boa umidade, há aumento da altura de plantas e da inserção das primeiras vagens em espaçamentos menores e/ou densidades maiores. Para o Estado do Paraná, os espaçamentos que melhor se adaptam estão entre 40 e $50 \mathrm{~cm}$ (EMBRAPA, 2011).

Ao ensilar uma leguminosa, não se podem esperar silagens com características de fermentação semelhantes à silagem-padrão, que é a de milho. Porém, observa-se que nos parâmetros mais definidores de qualidade, tais como o pH, ácidos orgânicos, nitrogênio amoniacal em relação ao total e matéria seca, a silagem de soja pode ser considerada de boa fermentação (qualidade). No que se refere aos aspectos de valor nutritivo, a silagem de soja supera a silagem padrão (milho) e comparando com produtos tais, como a silagem de capim, a silagem de soja é superior em teor de matéria seca, proteína bruta, menor teor de fibra em detergente neutro, maior consumo de proteína, maior digestibilidade da matéria seca e melhor balanço de nitrogênio (EVANGELISTA et al., 2003).

Para a produção da silagem de soja exclusiva, em cultivo isolado todo cuidado e recomendação para a produção devem ser respeitados com rigor. $\mathrm{O}$ corte da soja 
na fase de enchimento de grãos (estádio R5) é o momento mais recomendado para aliar rendimento e qualidade da forragem. A ensiladeira, para colher esse material, deve estar com as facas bem afiadas para proporcionar corte de 1,0 a 2,0 cm. Se for por processo mecanizado, devem-se utilizar máquinas que colham bem forragens de hastes mais finas, o que proporciona bom rendimento de colheita. Ao colocar o material no silo, é dispensável o uso de inoculante e a compactação da forragem deve ser bem feita do início ao final do enchimento do silo (WILLMS, 1997).

A média de produtividade entre diferentes estádios em dois anos de produção, de acordo com Willms (1997), na colheita de soja para silagem em estádio R4, a tonelagem aumentou $60 \%$ comparativamente à colheita no estádio R2. Já a colheita no estádio R6 teve aumento de $30 \%$ sobre a colheita no estádio R4.

Silagens colhidas no estádio R4 apresentaram menor digestibilidade do que silagens colhidas nas fases de R2 ou R6. Isto é explicado pelo fato da maior parte dos carboidratos estruturais formarem-se na fase de R4 e o rendimento do material de vagem aumentar substancialmente através do estádio R7. $\mathrm{Na}$ fase de R6, a digestibilidade de vagens é superior ao de hastes em $25 \%$, contribuindo significativamente para o valor nutritivo global de toda a planta (WILLMS, 1997; FRANCO, 2004; MAGALHÃES, 2007).

O grão de soja, por ser um vegetal com elevados teores de proteína e energia, constitui boa alternativa de alimento protéico, apresentando cerca de 17 a $18 \%$ de óleo e 35 a 37\% de proteína bruta de elevado valor biológico, com composição em aminoácidos essenciais favorável à alimentação animal (MENDES et al., 2004).
Para o corte, as plantas devem estar entre os estádios de R5 a R7, pois ao antecipar o corte, aumenta-se o teor de proteína da silagem, mas diminui-se a energia, devido a menor quantidade de óleo presente nos grãos, valores estes similares à silagem de milho, de 3 a 4\%. Quando ao contrário, atrasa-se o corte superior ao estádio R7, ocorre um aumento na energia ( 8 a 10\% de óleo) e redução no percentual de proteína. Conforme as fases de evolução da planta observam-se variações de 5 e $10 \%$ no teor de óleo e entre 15 e $20 \%$ no valor protéico (KEPLIN, 2004).

De acordo com trabalhos de Coffey et al. (1995) citado por Willms (1997), silagens de soja colhidas nos estádios R2 e R4 apresentaram vários graus de bolor, com odor desagradável e uma de cor verde escuro tendendo a preto. Já as silagens colhidas no estádio R6 raramente apresentaram mofo, mantendo uma cor semelhante às forragens recém-colhidas e liberavam um odor agradável.

Com relação ao uso de inoculantes, em trabalhos de Coffey et al. (1995) citados por Willms (1997), as diferenças na fermentação ruminal dos animais alimentados com silagens que possuíam inoculantes quando comparadas com silagens que não possuíam inoculantes, foram inconsistentes. Silagens colhidas nos estádios R4 e R6 com uso dos inoculantes apresentaram teores reduzidos de etanol, pois o etanol é um efeito indesejável do processo de fermentação da silagem. $\mathrm{Na}$ opinião deste nutricionista, o perfil nutricional de soja silagem tem-se uma boa oportunidade para utilização de um inoculante quando objetiva diminuir os teores de etanol das silagens de soja produzidas. Os teores de proteína encontrados foram elevados (> $15 \%$ de proteína bruta) em comparação com outros cereais forrageiros para silagens (por exemplo, silagem de milho). 
De acordo com Franco (2004), a inoculação é necessária e deve ser feita com produtos contendo três tipos de bactérias: a Lactobacillus plantarum, a Streptococcus faecium e a Lactobacillus salivarius, com o objetivo de acelerar a fermentação do material para evitar a desnaturação protéica da silagem e sua rancificação.

Conforme Munoz et al. (1983) avaliaram a digestibilidade in vitro $\mathrm{da}$ matéria seca da planta inteira de soja, encontraram que a digestibilidade permanece relativamente constante em cerca de $60 \%$ nas várias fases reprodutivas de crescimento (R1, R3, R5, R6 e R7), sendo que as folhas e vagens apresentaram uma digestão mais fácil (aproximadamente 68 a $72 \%$ de digestibilidade in vitro da matéria seca) do que caules (aproximadamente de 40 a $46 \%$ de digestibilidade in vitro da matéria seca). A digestibilidade dos caules diminuiu drasticamente na fase de início de desenvolvimento das vagens.

As vantagens do uso da silagem de planta inteira de soja, de acordo com Franco (2004) são: a redução na quantidade de grãos na dieta, rotação de culturas, produção de 2,5 vezes mais proteína por $\mathrm{kg}$ de matéria seca, alimento de alto nível de nutrientes digestíveis totais superiores ao do milho e redução de até 30\% nos custos. As limitações, de acordo com a autora, seria a competição econômica com a soja-grão, mito da soja como não forrageira, necessidade de pesquisas para identificar cultivares para ensilagem, não poder ser usada como volumoso único, exigência de máquinas para colheita me maior escala que tenham capacidade para picagem adequada e maior atenção à fermentação.

\section{Misturas de soja com gramíneas para silagem}

A justificativa para o uso de soja associada a uma gramínea para ensilar é principalmente a elevação do teor de proteína bruta da silagem, que quando feita exclusivamente com gramínea, apresenta, em média, valores de 4,0 a 7,0\% (base na matéria seca), dependendo da forrageira empregada. A soja, colhida no estádio de início de enchimento de grãos (estádio R5), pode apresentar $18 \%$ de proteína bruta na matéria seca da forragem. Com base em estudos realizados por Silva et al. (2000a) e Evangelista et al. (2003), pode-se concluir que a inclusão de soja junto ao milho, sorgo ou capim contribui para a melhoria do valor nutritivo da silagem, levando a maior consumo de forragem e, conseqüentemente, a maior produção animal. A soja, em relação a outras leguminosas, apresenta características mais favoráveis para a mistura na produção de silagem, destacando a maior disponibilidade de sementes no mercado, maior contribuição para a elevação da matéria seca e proteína da silagem.

Entretanto, Lempp et al. (2000) descreveram que dependendo da concentração de soja na consorciação com o milho, poderá ocorrer redução do nível de carboidratos solúveis e elevado poder tamponante, que prejudicam a fermentação láctica e a redução do $\mathrm{pH}$ da silagem.

Eichelberger et al.(1997) encontraram que a adição de altas concentrações de soja (10-50\%) associadas ao milho elevou os teores de proteína bruta, $\mathrm{Ca}$ e $\mathrm{P}$, mas reduziu o teor de matéria seca e elevou o $\mathrm{pH}$ das silagens, sem influenciar a digestibilidade in vivo da matéria seca. 


\section{Cultivos isolados de soja, milho ou sorgo}

A forragem pode ser resultante de culturas isoladas e a mistura feita associando o material para trituração ou ao colocar o material triturado dentro do silo. Podem ser formadas áreas semelhantes das culturas de milho ou o sorgo para associação, e as produções, devido às características das duas culturas, já terão rendimentos proporcionais ao que será empregado para ensilar, que, neste caso, pode ser de 30 a 50\% de soja, salientando que milho e o sorgo produzem 30 e $40 \mathrm{t} / \mathrm{ha}$ de massa verde em média, respectivamente, e a soja, 18 a 30 toneladas por hectare, dependendo do nível de tecnologia. Devese tomar cuidado com a escolha da cultivar de soja, que deverá ser de ciclo médio, para ser colhida na fase de enchimento de grãos, com 100 a 120 dias (EVANGELISTA et al., 2003).

$\mathrm{Na}$ rotação de culturas associada à silagem de milho de parte aérea, com colheita das plantas a $40 \mathrm{~cm}$ com $90 \mathrm{~cm}$ do solo, garante-se maior percentual de grãos no volumoso, elevando o teor protéico e energético desse alimento. Com uma mistura de $60 \%$ de silagem de milho de parte aérea mais $40 \%$ de silagem de soja, consegue-se trabalhar com quantidades menores de concentrado do que o usualmente oferecido aos animais quando não se utiliza suplementação à base de silagem de soja (FRANCO, 2004).

$\mathrm{Na}$ dificuldade de obtenção de semente de ciclo médio, pode-se antecipar ou retardar o plantio dessa leguminosa, de tal forma que o ponto de colheita coincida com a colheita do milho ou sorgo. A associação da soja na ensilagem de gramíneas, embora mude as características da fermentação no silo, não prejudica a qualidade da forragem, elevando o teor de proteína, mantendo o $\mathrm{pH}$ a valores inferiores de 4, o teor de ácido lático entre $6 \mathrm{e}$ $8 \%$ e o teor de nitrogênio amoniacal em níveis abaixo de $10 \%$ na silagem mista. A associação da soja nas proporções de 20 ou $40 \%$ em peso, em relação ao milho exclusivo, contribui para aumentar o consumo de matéria seca, de proteína bruta e de energia metabolizável. Além do aumento de proteína na silagem, a adição de soja tem efeito marcante sobre os teores de minerais, principalmente fósforo (GRIFFIN, 2000; EVANGELISTA et al., 2003).

\section{Diferentes arranjos culturais para cultivos de soja com milho e sorgo}

Para a produção da forragem sojagramínea, pode-se utilizar a formação das culturas em linhas intercaladas ou em faixas. Nesse caso, além da produção da silagem mista, objetiva-se aproveitar os benefícios que podem ocorrer com a diversificação de culturas na mesma área ou ainda os benefícios da rotação de culturas, haja vista que em semeio posterior, soja e milho não ocuparão o mesmo lugar do primeiro cultivo. Nesse método de cultivo podem-se fazer diversos arranjos culturais, conforme conveniência e equipamentos disponíveis para semeio e colheita, e que, os rendimentos obtidos por área são equivalentes ao da gramínea exclusiva, uma vez que o espaçamento entre linhas a ser usado deve ser entre 0,4 e 0,5 metros (EVANGELISTA et al., 2003; FRANCO, 2004).

Em exemplo dos efeitos observados para a associação da soja com gramíneas oriundas de cultivos isolados, nos produtos dos cultivos em faixas, também são observados que a digestibilidade da matéria seca e o teor 
de carboidratos não são alterados e o teor de proteína da silagem mista é superior ao da gramínea exclusiva (GRIFFIN, 2000; EVANGELISTA et al., 2003). Neste contexto, a utilização da soja nos sistemas consorciados em linhas intercaladas proporciona alguns benefícios, justificando sua maior utilização no material ensilado. Outro fator a considerar é que as plantas de soja e sorgo têm comprovado poder de rebrota após o corte, podendo fornecer em conjunto mais forragem por unidade de área em consórcio quando comparado ao monocultivo da gramínea. Após os cortes, as plantas irão rebrotar, podendo essa rebrota ser utilizada novamente na forma de forragem ou de grãos, dependendo da necessidade do agricultor (SILVA et al., 2000b).

\section{Cultivos de soja, milho ou sorgo em consórcio para silagem de planta inteira}

Podemos lançar mão das culturas em consórcio, que alia os benefícios da rotação e da diversificação de culturas na mesma área, havendo os pontos positivos do consórcio gramínea e leguminosa, tais como o aproveitamento de luz solar e nutrientes do solo, tolerância do cultivo misto a pragas e doenças e, ainda torna-se fácil a colheita do material já associado a partir do campo. As populações de milho e de sorgo devem ser oriundas de densidades de semeio de $4 \mathrm{e}$ 12 plantas por metro linear, respectivamente, acompanhadas de 25 a 30 plantas de soja por metro quadrado. A adubação é determinada de acordo com as exigências da gramínea, e a leguminosa aproveita o excedente do fertilizante colocado, não havendo necessidade de fertilização específica para a soja. As cultivares tem que possuir ciclos compatíveis, para que o ponto de colheita do milho ou sorgo, em estádio de grãos farináceos, coincida com o momento ideal de colheita para soja (EVANGELISTA et al., 2003).

Os efeitos benéficos da associação soja-gramínea são observados também sobre a produtividade da área explorada. As áreas cultivadas por esse método rendem, no mínimo, a área cultivada com gramínea isolada e com o fato positivo de se conseguir forragem de melhor qualidade e valor nutritivo. As justificativas para os melhores dados de produção obtidos nos consórcios são o melhor aproveitamento do nitrogênio, que pode ser elevado em até quatro vezes. Somam-se a esses efeitos de campo os efeitos na nutrição dos animais, onde o uso da silagem mista gera economia de concentrados protéicos, como é ocaso dos farelos de soja e algodão, com ganhos de peso equivalentes aos destes produtos quando fornecidos, bem como o uso de uréia (REZENDE et al., 2000; EVANGELISTA et al., 2003).

Desta forma, uma das alternativas que os produtores podem lançar mão para melhorar o valor nutritivo do alimento fornecido na época de escassez e diminuir os custos de suplementação protéica é a utilização de alimentos ricos em proteína produzidos na própria fazenda. Neste particular, o consórcio sorgo-soja, tem-se destacado, pois esta leguminosa não diminui a produtividade forrageira, aumenta o teor de proteína da silagem e proporciona ganhos de peso significativamente maiores (SILVA et al., 2003; REZENDE et al., 2004; SILVA et al., 2004).

No Brasil, as publicações a respeito desse assunto vêm mostrando um avanço no que se refere às técnicas de uso dessa prática, bem como novos arranjos culturais e proporções de misturas, com resultados que 
levam a crer que a associação de gramínea com a leguminosa para ensilar é promissora (SILVA et al., 2003).

\section{Potencial de produção e valor nutricional da silagem de planta inteira de soja}

O produtor deve avaliar que sempre existirá a competição da silagem de soja com a venda dos grãos. A capacidade da silagem de soja em reduzir a fração concentrada na dieta está diretamente associada ao seu alto valor nutricional. Ela possibilita produzir 2,5 vezes mais proteína bruta por quilo de matéria seca, em comparação com a silagem de milho (18\% contra $7 \%$ ), além de ter índice de nutrientes digestíveis totais, superior ao desse alimento (74\% contra $70 \%)$, além de apresentar um nível de óleo que tem variado de 6 a 10\% (KEPLIN, 2004).

Em trabalho realizado por Magalhães (2007) que objetivou determinar o valor energético de diferentes volumosos utilizados na dieta de bovinos (silagem de cana + uréia, silagem de soja, silagem de mombaça + uréia, silagem de milho + uréia), com utilização de 28 novilhas Nelore, em regime de confinamento, com $293 \mathrm{~kg}$ de peso vivo médio, alimentadas com volumoso exclusivo na dieta de silagem de soja durante 12 dias. Os resultados encontrados foram de 20,65\% de matéria seca - MS; 20,18\% de proteína bruta - PB; $12,62 \%$ de extrato etéreo - EE; $46,27 \%$ de fibra em detergente neutro corrigida para proteína - FDNp; 45,40\% de fibra em detergente neutro corrigida para cinzas e proteína - FDNcp; 59,88\% de carboidratos totais - CHOT; $14,48 \%$ de carboidratos não fibrosos -CNF; $10,43 \%$ de lignina - LIG; e 1,36\% de proteína insolúvel na fibra em detergente ácida - PIDA. Os resultados de $\mathrm{PB}, \mathrm{EE}, \mathrm{LIG}$ e PIDA foram maiores que os encontrados nos outros tratamentos, enquanto que os resultados de MS, FDNp, FDNcp, CHOT e CNF foram menores.

Quando se misturam os dois tipos de silagens usando-se $60 \%$ de milho e $40 \%$ de soja, consegue-se elevar em $50 \%$ o percentual de proteína bruta na ração total e aumentar o teor de energia em 3 ou 4\%, ou seja, em média a silagem de milho contribui com $7 \%$ de proteína bruta e a de soja com $17 \%$, consequentemente a mistura proporciona um volumoso com uma média de 11\% (KEPLIN, 2004).

Segundo St-Pierre et al. (2002), a composição nutricional da silagem de soja irá variar dependendo do momento do corte da planta para ensilagem, tendo como valores médios, de $35 \%$ de matéria seca, $18 \%$ de proteína bruta, $82 \%$ de proteína degradável e 45,7\% fibra em detergente neutro total. Para garantir uma boa silagem, os autores recomendam a mistura de uma parte de soja para uma parte de milho no momento da ensilagem.

Ao longo de 10 anos avaliando e utilizando a soja como fonte de volumoso, Keplin (2004) observou que o menor valor encontrado de proteína bruta foi de 14,9\%, enquanto o maior foi de $24 \%$; o teor de óleo variou de 3,5 a $14 \%$; o teor de matéria seca de 26 a 33\%; os valores de fibra em detergente ácido ao redor de $30 \%$, levemente superiores ao da silagem de milho, enquanto os valores de fibra em detergente neutro de $40 \%$, pouco inferiores aos da silagem de milho; fibra bruta de $32 \%$ e média de extrato etéreo de $23 \%$, com produção de 30 toneladas por hectare (KEPLIN, 2004).

Dentre os fatores limitantes para uso de forrageiras tropicais, cita-se o poder tampão que é relativamente alto em função 
da quantidade de ácidos orgânicos presentes na forragem. Os ácidos orgânicos são o ácido málico, ácido cítrico e ácido aspártico, podendo também estar presente o ácido oxálico, que agem com efeitos tamponantes, impedindo a queda do $\mathrm{pH}$ da massa ensilada (inibidor da ação do ácido lático). Além do nível de carboidrato na forragem a ser ensilada que é afetado por fatores como a radiação solar no dia de corte, pois dias ensolarados provocam uma maior deposição de açucares na forragem do que dias nublados. Esta variação é da ordem de 2 a 3 unidades porcentuais para a mesma espécie de forrageira entre dias nublados e com sol pleno, aliado ao horário de corte, onde os níveis de açucares, na mesma espécie de forrageira, são maiores no final do dia $(17 \mathrm{~h}$ horas) do que pela manhã e esta variação pode alcançar valores de 2 unidades porcentuais. A extensão do período de emurchecimento que em período muito longo (> 24 horas) reduz o conteúdo em carboidratos da forragem a ser ensilada podendo alcançar valores de 3 a 4 unidades, dependendo da área de exposição do material picado, assim como a exposição à chuva no campo que lixiviará os carboidratos e aumentará a respiração das células (VILELA, 2007).

Outro fator que deve ser observado é a compactação da forragem que reduz a fase aeróbica e unida a um fechamento rápido do silo, irá melhorar a anaerobiose, resultando em menor perda de açucares através da respiração. Quando se tem valor de $2 \%$ de carboidratos solúveis na matéria orgânica da forragem, fatalmente obterse-á uma silagem escura, com alto teor de ácido butírico e baixo valor nutritivo. Este valor corresponde a menos de 14\% de carboidratos solúveis na matéria seca (VILELA, 2007).
É importante adaptar os animais que irão receber essa dieta, oferecendo nos primeiros dez dias de confinamento apenas silagem de milho e soja devido à quantidade de grãos presentes (em torno de $30 \%)$. Do $11^{\circ}$ ao $20^{\circ}$ dia de confinamento, inicia-se o fornecimento do concentrado acrescentando-se, diariamente, $10 \%$ de concentrado (FRANCO, 2004).

Para avaliar o custo de insumos e operacional versus a produção de matéria seca e $\mathrm{kg}$ de porteína burta em função da produção de grãos, o preço final para silagens muito úmidas (menos de 30\% de matéria seca) e muito secas (superior a 38\% de matéria seca), deve ser recalculado, ajustado para teor de matéria seca. Silagem de soja muito úmida não fermentará adequadamente e têm elevado potencial para baixa ingestão pelos animais. Já a ensilagem de soja muito seca não fermentará adequadamente e irá resultar em menor digestibilidade devido à presença de mofos no produto final. Esta silagem provavelmente terá menores teores de proteína bruta e fibra em detergente neutro em níveis mais elevados devido ao excessivo murchamento da folha durante a colheita, com durabilidade inferior do que plantas ensiladas com bom nível de umidade (ST-PIERRE et al., 2002).

\section{Considerações Finais}

A falta de informações para o uso da silagem de soja como alimentação em períodos críticos decorre do hábito do produtor especializado em produção de soja direcionar essa cultura para a produção de grãos e os pecuaristas não visualizarem na soja uma opção forrageira viável economicamente. $\mathrm{O}$ uso da soja como silagem para alimentação animal diminui 
os custos com o confinamento, sendo uma fonte alternativa de proteína, livrando os produtores da dependência dos valores alternados do mercado de grãos, além de possibilitar a rotação de culturas em áreas que produzam milho para silagem. Trata-se de um produto de interesse do ponto de vista nutricional que apresenta cultivo bastante conhecido e com volume considerável de informações tecnológicas disponíveis. Cabe ao produtor fazer a análise dos custos de alimentação dos seus animais de produção quanto à compra de concentrados para perceber que a silagem de planta inteira de soja vem demonstrando valores mais satisfatórios para a suplementação animal.

\section{Referências}

BARBOSA, F. A.; GRAÇA, D. S.; SOUZA, G. M. Integração Lavoura - Pecuária: Aspectos produtivos na pecuária bovina. Portal Agronomia. Disponível em: <http:// www.agronomia.com.br/conteudo/central_links/especiais/artigos_cientificos.htm $>$. Acesso em: 3 maio 2008.

CORTE, E.; REZENDE, P. M.; ANDRADE, L. A. D. de, PINHO, R. G. V.; GOMES, L. L. Consórcio sorg-soja. VII. Sistemas de corte no rendimento forrageiro das culturas consorciadas. Ciência e Agrotecnologia, Lavras, v.27, n.3, p.681-688, 2003.

EICHELBERGER, L.; SIEWERDT, L.; SILVEIRA JUNIOR, P. Efeitos da inclusão de níveis crescentes de forrajem de soja e uso de inoculante na qualidade da mifagem de milho. Revista Brasileira de Zootecnia, v. 26, n. 5, p. 867-874, 1994.

EMPRESA BRASILEIRA DE PESQUISA AGROPECUÁRIA - EMBRAPA. Soja no Brasil: calagem, adubação e nutrição animal. Londrina: Embrapa Soja, 2008. 148 p.

EMPRESA BRASILEIRA DE PESQUISA AGROPECUÁRIA - EMBRAPA SOJA. Soja em números (safra 2010/2011). 2011. Disponível em: <http:// <http://www.cnpso. embrapa.br/index.php?cod_pai=2\&op_page=294>. Acesso em: 22 ago. 2011.

EMPRESA BRASILEIRA DE PESQUISA AGROPECUÁRIA - EMBRAPA SOJA. Tecnologias de Produção de Soja- Região Central do Brasil 2011. Londrina: Embrapa Soja, 2010. 255p.

EMPRESA BRASILEIRA DE PESQUISA AGROPECUÁRIA - EMBRAPA SOJA. Sistema de alerta Embrapa Soja. 2007. Disponível em: <http: <http://www.cnpso.embrapa. br/alerta/ver_alerta.php?cod_pagina_as=80\&cultura=1>. Acesso em: 19 mar. 2008.

EMPRESA BRASILEIRA DE PESQUISA AGROPECUÁRIA - EMBRAPA SOJA. Tecnologias de Produção de Soja- Paraná 2007. Londrina: Embrapa Soja, 2006. 216p.

EVANGELISTA, A. R.; RESENDE, P. M.; MACIEL, G. A. Uso da soja [Glycine max (L.) Merrill] na forma de forragem. Lavras: UFLA, 2003. 36p. 
FRANCO, M. Loucura que deu certo. DBO-A Revista de Negócios do Criador, São Paulo, n.279, p.76-83, 2004.

GRIFFIN, T. Soybean Silage as an Alternative Forage. Disponível em: <http://www.umaine. edu/livestock/Publications/soybean_silage.htm>. Acesso em: 18 mar. 2008.

INSTITUTO BRASILEIRO DE GEOGRAFIA E ESTATÍSTICA - IBGE. Levantamento Sistemático da Produção Agrícola. Disponível em: <http://www.ibge.gov. $\mathrm{br} /$ home/presidencia/noticias/noticia_visualiza.php?id_noticia=1898\&id_pagina=1 >. Acesso em: 22 ago. 2011.

KEPLIN, L. A. S. Silagem de soja: uma opção para ser usada na nutrição animal. In: SIMPÓSIO SOBRE PRODUÇÃO E UTILIZAÇÃO DE FORRAGENS CONSERVADAS, 2., 2004, Maringá. Anais... Maringá: Universidade Estadual de Maringá, UEM, 2004. p.161-171.

KUSS, R. C. R. Populações de plantas e estratégias de irrigação na cultura de soja. 2006. 81f.Dissertação (Mestrado em Engenharia Agrícola) - Universidade Federal de Santa Maria, Santa Maria, RS, 2006.

LEMPP, B.; MORAES, M. G.; SOUZA, L. C. F. Produção de milho em cultivo exclusivo ou consorciado com soja e qualidade de suas silagens. Arquivo Brasileiro de Medicina Veterinária e Zootecnia, Belo Horizonte, v.52, n.3, p. 243-249, 2000.

MAGALHÃES, K. A. Tabelas brasileiras de composição dos alimentos, determinação e estimativa do valor energético dos alimentos para bovinos. 2007. 281f. Tese (Doutorado em Zootecnia) - Universidade Federal de Viçosa, Viçosa, 2007.

MENDES, W. S.; SILVA, I. J.; FONTES, D. O.; RODRIGUES, N. M.; MARINHO, P. C.; SILVA, F. O.; AROUCA, C. L. C.; SILVA, F. C. O. Composição química e valor nutritivo da soja crua e submetida a diferentes processamentos térmicos para suínos em crescimento. Arquivo Brasileiro de Medicina Veterinária e Zootecnia, Belo Horizonte, v.56, n.2, p.207-213, 2004.

MUNOZ,A.E.; HOLT,E.C.;WEAVER,R.W.Yield and quality of soybean hay as influenced by stage of growth and plant density. Agronomy Journal, Madison, v. 75, p. 147-148, 1983.

REZENDE, P. M; SILVA, A. G.; CORTE, E.; BOTREL, E. P. Consórcio sorgo-soja. VI. Estudo comparativo em função da rebrota de cultivares de sorgo e soja consorciados na entrelinha e em monocultivo no rendimento de forragem. Ciência e Agrotecnologia, Lavras, v.24, (Edição Especial), p.215-223, 2000.

REZENDE, P.M.; SILVA, A. G.; BOTREL, E. P.; GOMES, L. L.; GRIS, C. F. Consórcio sorgo-soja. VIII. Sistemas de corte, cultivares de soja e híbridos de sorgo na produção de forragem das culturas consorciadas na entrelinha e monocultivo de sorgo. Revista Brasileira de Agrociência, Pelotas, v.10, n.4, p.475-481, 2004. 
ROCHA, M. M. Seleção de linhagens experimentais de soja para adaptabilidade e estabilidade fenotípica. 2002. 173f. Tese (Doutorado em Genética e Melhoramento de Plantas) - Escola Superior de Agricultura Luiz de Queiroz, Piracicaba, SP, 2002.

SILVA, A. G.; REZENDE, P. M.; CORTE, E.; MANN, E. N. Consórcio sorgo-soja. III. Seleção de cultivares de sorgo e soja, consorciadas na linha, visando à produção de forragem. Ciência e Agrotecnologia, Lavras, v.24, n.4, p.861-868, 2000a.

SILVA, A. G.; REZENDE, P. M.; ANDRADE, L.A. B.; EVANGELISTA, A. R. Consórcio sorgo-soja. I. Produção de forragem de cultivares de soja e híbridos de sorgo, consorciados na linha, em dois sistemas de corte. Ciência Rural, Santa Maria, v.30, n.6, 2000 b.

SILVA, A. G.; REZENDE, P. M; GRIS, C. F.; GOMES, L. L; BOTREL, E. P. Consórcio sorgo-soja. IX. Influência de sistemas de cortes na produção de forragens de sorgo e soja consorciados na linha e de sorgo em monocultivo. Ciência e Agrotecnologia, Lavras, v.27, n.2, p.451-461, 2003.

SILVA, A. G. da; REZENDE, P. M; TOURINO, M. C. C.; GOMES, L. L.; GRIS, C. F. Consórcio sorgo-soja. X. Seleção de híbridos de sorgo e cultivares de soja para a produção de forragem. Revista Brasileira de Agrociência, Pelotas, v.10, n.2, p.179-184, 2004.

ST-PIERRE, N.; WEISS, B.; SHOEMAKER, D. Pricing Standing Soybeans for Silage. Disponível em: <http://dairy.osu.edu/resource/feed/Princing\%20Standing\%20Soybeans\%20 for\%20Silage-revised.pdf.>. Acesso em: 20 mar. 2008.

VILELA, H. Silagem de gramínea (capim) tropical. Portal Agronomia. Disponível em: $<$ http://www.agronomia.com.br/conteudo/artigos/artigos_silagem_graminea.htm >. Acesso em: 3 maio 2008.

WILLMS, C. L. Drought Contingency Plan: Using Soybeans as Forage - Silage or Hay. Disponível em: < http://www.beeflinks.com/soybean_silage.htm>. Acesso em: 18 mar. 2008. 